\title{
Neuroptera of the Amazon Basin. Part 2. Dilaridae
}

\author{
Norman D. Penny ( ${ }^{(+)}$
}

\begin{abstract}
Three new species of Nallachius (Neuroptera: Dilaridae) are described from the Amazon Basin.
\end{abstract}

\section{INTRODUCTION}

The neuropteran family Dilaridae is one of the smallest and least known of the Neuroptera, even though the geographical distribution is quite widespread. Adams (1970) in his revision of New World Dilaridae listed 13 species in one genus, ranging from Michigan in northern U.S.A. south to Argentina. However, 11 of these species are known from only one locality and none have previously been recorded from the Amazon Basin. The present study describes three new species of Nallachius from this region.

\section{BIOLOGY}

Very little is known of the biology of Dilaridae. MacLeod \& Spiegler (1961) found larvae of Nallachius americanus (MacLachlan) under the bark of recently dead trees. Other larvae were found in more decayed wood. They appear to be predators and were successfully reared on soft-bodied insect larvae and eggs.

\section{Systematics}

The Dilaridae are subdivided into two subfamilies: Dilarinae in the Eastern Hemisphere and Nallachiinae in the Western Hemisphere (Adams, Ibid.). Three genera have been described from the Americas - Nallachius Navás, Nulema Navás and Neodilar Carpenter. In the most recent revision Adams (Ibid.) places the last two genera in synonomy with the first. He further recognizes three species groups - the "pulchellus" group in which the second posterior medial vein (MP2) is not coalesced with the anterior cubital vein (CuA) in the forewing. the "limai" group with broad, rounded wings and much secondary branching of the longitudinal veins, and the "americanus" group with MP2 fused with CuA. The present study describes one new species from the "americanus" group.

\section{Genus Nallachius Navás \\ (Fig. 1)}

Nallachius Navás, 1909, Mems. R. Acad. cienc. artes Barcelona, 7:665.

Nulema Navás, 1914, Gen Insect., 156:12.

Neodilar Carpenter, 1947, Psyche, Camb., 54:107.

Type Species: of Nallachius is Dilar prestonı MacLachlan, designated by Navás, 1914; of Nulema is Nulema championi Navás by original designation; of Neodilar is Dilar hermosa Banks by original designation.

Head: Flattened and somewhat elongate. One medial, two lateral setiferous tubercles on vertex. Mouthparts tiny, partly sunken within anterior portion of head. Compound eyes very large, laterally prominent. Ocelli absent. Male antennae flabellate, of 10 to 16 segments. Female antennae filiform, of about 16 segments. Thorax: Pronotum setiferous, flattened, quadrate. Pleural region elongate. Conical coxa; short, quadrate trochanter; elongate, pilose tibia and femur; five-segmented tarsi, with first segment elongate, last segment swollen; two tarsal claws. Tibial spurs absent.

Wings: Oblong to rounded, very pilose, pale with dark pattern. Forewing length in male 2.9 to $16 \mathrm{~mm}$; in female 5.1 to $22.5 \mathrm{~mm}$. Costal area with numerous crossveins. Much branching of longitudinal veins at wing margin. MA appearing as branch of Rs.

Abdomen: Ten abdominal segments with prominent, pilose tubercles at anterior margin of anterior tergites. Female bearing long, recurved ovipcsitor over abdomen; male bearing a series of small tubercles and more elongate, sclerotized gonocoxites.

(*) - Instituto Nacional de Pesquisas da Amazônia, Manaus. 
1a. In forewing, MP2 fused with CuA, costal veinlets simple (ameri-

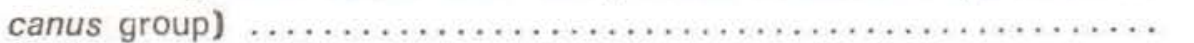

1b. In forewing, MP2 not fused with CuA, some costal veinlets occasion-

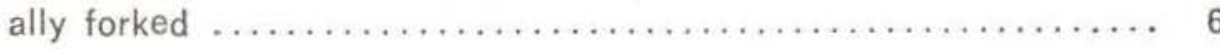

2a. Wing apex rounded, nearly symmetrical about long axis $\ldots \ldots \ldots 3$

2 b. Wing apex plainly asymmetrical, posterior margin angulate $\ldots \ldots \ldots 4$

3a. In forewing, four Rs branches beyond fused MA (Amazon) .......

N. maculatus

3b. In forewing, three Rs branches beyond fused MA (Paraguay) ....

N. pupillus

4a. More than 2 radial crossveins in forewing; several crossveins between branches of Rs in both wings (Ecuador) .................

N. loxanus

4b. Only two radial crossveins in forewing, no crossveins between

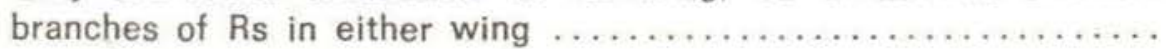

5a. Dorsal lobes of male ectoprocts broadly tapering to distal point: digitiform process much smaller than dorsal lobes (North America

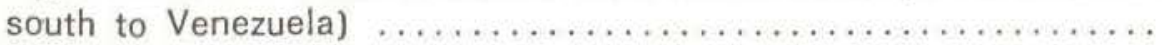

N. americanus

5b. Dorsal lobes of male ectoprocts narrowly elongate, with rounded tip; digitiform process almost as large as dorsal lobes (Amazonia) ....

6a. Male antennae with 16 elongate processes (Guatemala) .........

6b. Male antennae with 14 or fewer elongate processes $\ldots \ldots \ldots \ldots \ldots$

7a. Wings rounded; male genitalia with dorso-lateral plate of gonarcus

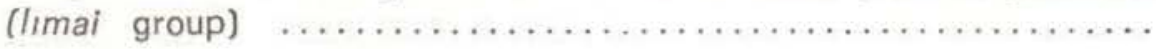

N. adamsi

N. championi

7

N. limai

7b. Wings more elongate; male genitalia lacking dorso-lateral plate of gonarcus (pulchellus group, except $N$. championi) ..............

8a. Dorsal lobe of ectoproct inflated, costal veinlets simple (Cuba and

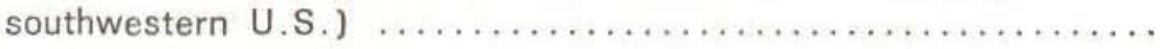

8b. Dorsal lobe of ectoproct flat $\ldots \ldots \ldots \ldots \ldots \ldots \ldots \ldots \ldots \ldots \ldots \ldots \ldots \ldots \ldots \ldots \ldots \ldots$

9a. Dorsal lobes of ectoprocts approximated on midline $\ldots \ldots \ldots \ldots .10$

$9 \mathrm{~b}$. Dorsal lobes of ectoprocts widely separated in middle ........ 11

10a. Costal area wider, most distal costal veinlets forked (sou. Brazil)

10b. Costal area narrow, most costal veinlets simple (southern Brazil)

N. ovalis

N. dicolor

11a. Subcosta nearly straight, costal area narrow, many costal veinlets forked (southern Brazil)

N. prestoni

11b. Subcosta curved posteriad at stigma, costal area wider, few costal

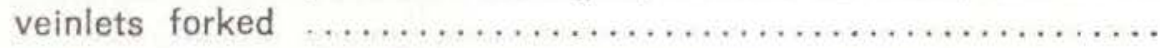

12a. Gonocoxites apically expanded in blade-shape; digitiform process

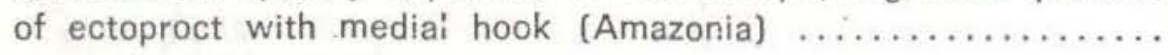

N. infuscatus

12b. Gonocoxites slender, not apically expanded; digitiform process of

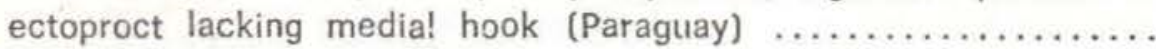

(") - Modified from Adams, 1970. 


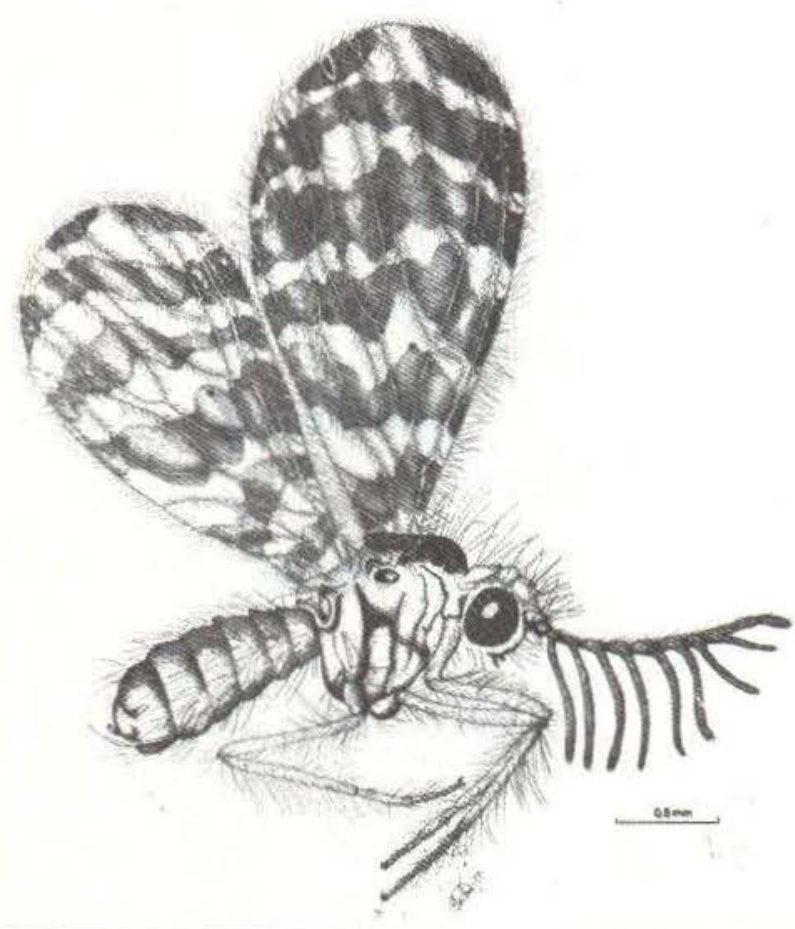

Fig. 1 - Lateral view of Nallachius ovalis Adams (reprinted from Penny and Arias, 1981) (drawn by Artemio Coelho da Silva).

Nallachius adamsi, n.sp.

(Figs, 3, 6, 9)

Original description based on four males on slides.

Head: Reddish brown. Mouthparts tiny; labrum pale. Maxillary palpi three-segmented. Labial palpi reduced to small papillae. Antennae 12segmented, with segmented $2-10$ bearing long. apical appendages in males.

Thorax: Diffuse, dark fuscous pigment covering meso- and metanota. Pleural region pale fuscous; coxa trochanter, femur and basal part of tibia pale. Apical part of tibia and tarsal segments pale fuscous.

Forewing: Pale with numerous, small, dark fuscous spots. Four spots on costal margin. the largest one about halfway to wing apex. Four spots, evenly spaced along anal margin. Costal crossveins numerous with short intercalary veins between. Radial sector (Rs) theree-branched with terminal twiggings. Anterior medius (MA) appearing as lower branch of P.s. Posterior medius (MP2) fused with anterior oubitus (CuA) (Fig. 3).
Abdomen of Male: Abdominal segments 2-8 with dorsal, setiferous tubercles. Gonocoxites long, stoutly pointed, with longitudinal groove and subapical notch; connected basally by arched gonarcus. Between gonocoxites two shorter, acutely pointed mediuncus lobes. Mediuncus lobes basally complexly curved and closely epproximated. Digitiform process of ectoproct well-deve!oped, tapering to acute point. Dorsal lobe of ectoproct long. narrow everily rounded at apex, with apical dark pigmentation (Figs. 6,9).

Body Length: male, $2.3 \mathrm{~mm}$.

Forewing Length: male, $4.1 \mathrm{~mm}$.

Geographical Distribution: Material in the Systematic Entomology Collections of INPA. Manaus include: BRAZIL: Amazonas, Reserva Ducke, km 26 - AM 010, 6-XII-1977, J.R. Arias, $i$ male; Amazonas, Reserva Ducke, km 26. AM
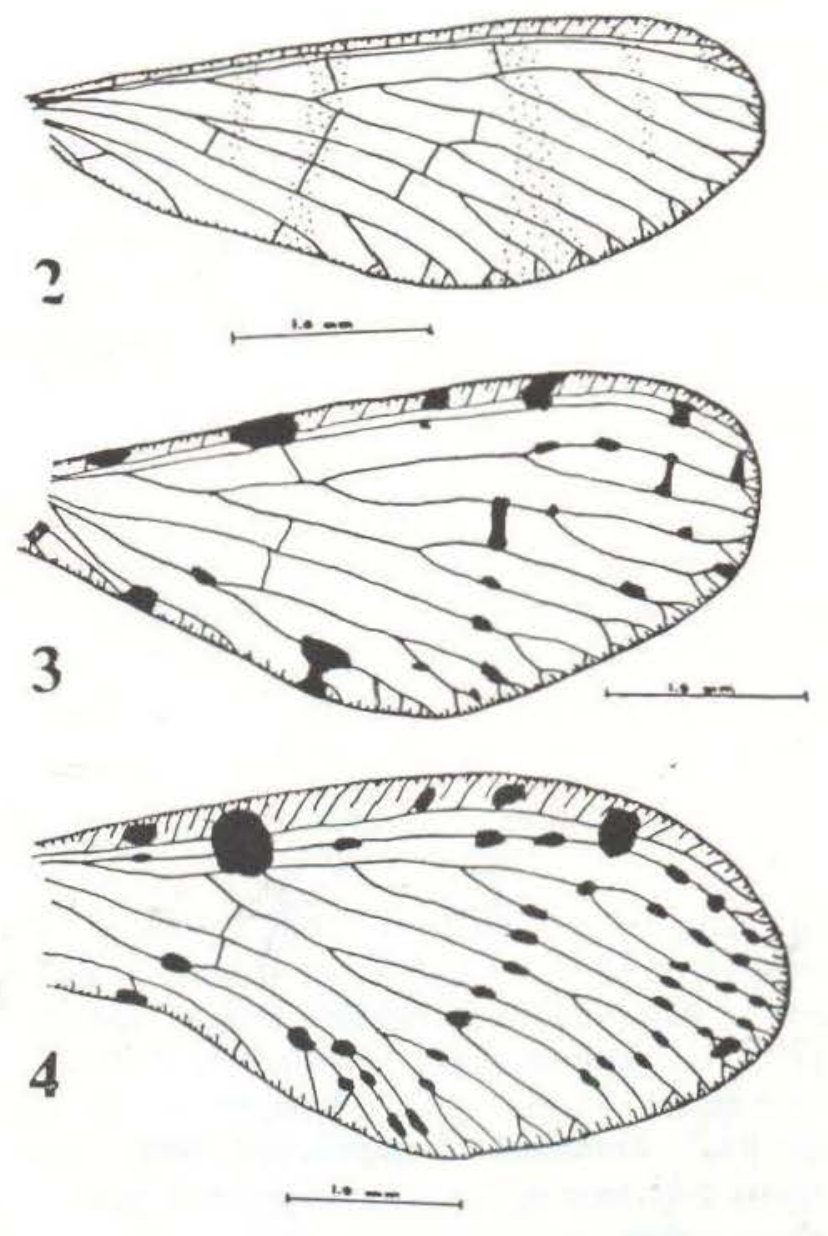

Figs. $2-4$ - Right forewing of 2) Nallachius infuscatus, n. sp., 3) Nallachius adamsi n. sp., 4) Nallachius maculatus, n. sp. 
010, 6-VII-1978, J.R. Arias, 1 male; Amazonas, Manaus, 29-V-1978, J.R. Arias, 1 male. One additional paratype in the collection of Phillip A. Adams from Amazonas, AM 010, $\mathrm{km} \mathrm{246,}$ 15-VII-1979, J.R. Arias, 1 male (Map 2) .

Temporal Distribution: Collections of Amazonian specimens have been made in May, June. July and December. It appears that there are at least two broods per year, or perhaps emergence does not occur in broods.

This species is a member of the americanus group which includes four other species, $N$. americanus (MacLachlan), N. loxanus Navás, N. maculatus and N. pupillus. N. adamsi can be separated from the latter two species by its expanded anal region of forewings, creating a wing which is very asymmetrical along the long axis. The radial crossveins separates it from $N$. loxanus. This species is most certainly closely related to $N$. americanus, but differs in some fine details of the male genitalia. In N. adamsi the gonocoxites are stouter, with a subapical notch, which is absent in $N$. americanus. The mediuncus lobes are basally much more sharply curved, and the dorsal lobes of the ectoprocts are apically rounded, not acutely pointed in $N$. adamsi.

This species is named for Dr. Phillip A. Adams, a leading specialist on South American Neuroptera.

Holotype male (from Manaus) in the Systematic Entomology Collections of INPA, Manaus. Paratype males in Museu de Zoologia, USP, São Paulo, Brazil; United States National Museum, Washington, D. C., U.S. A.; and collection of Phillip A. Adams, Fullerton, California.

\section{Nallachius infuscatus, n.sp.}

(Figs. 2, 5, 8)

Original description based on 32 males, 2 females on slides; 4 males, 1 female in alcohol. Head: Pale yellow to reddish brown. Mouthparts tiny: labrum pale. Maxillary palpi threesegmented, Labial palpi reduced to small papillae. Antennae 12-segmented, with segments 2-11 bearing long, apical appendages.

Thorax: Diffuse, dark fuscous pigment covering meso- and metanota. Pleural region pale fuscous to pale yellowish. Legs with diffuse, pale fuscous coloration.
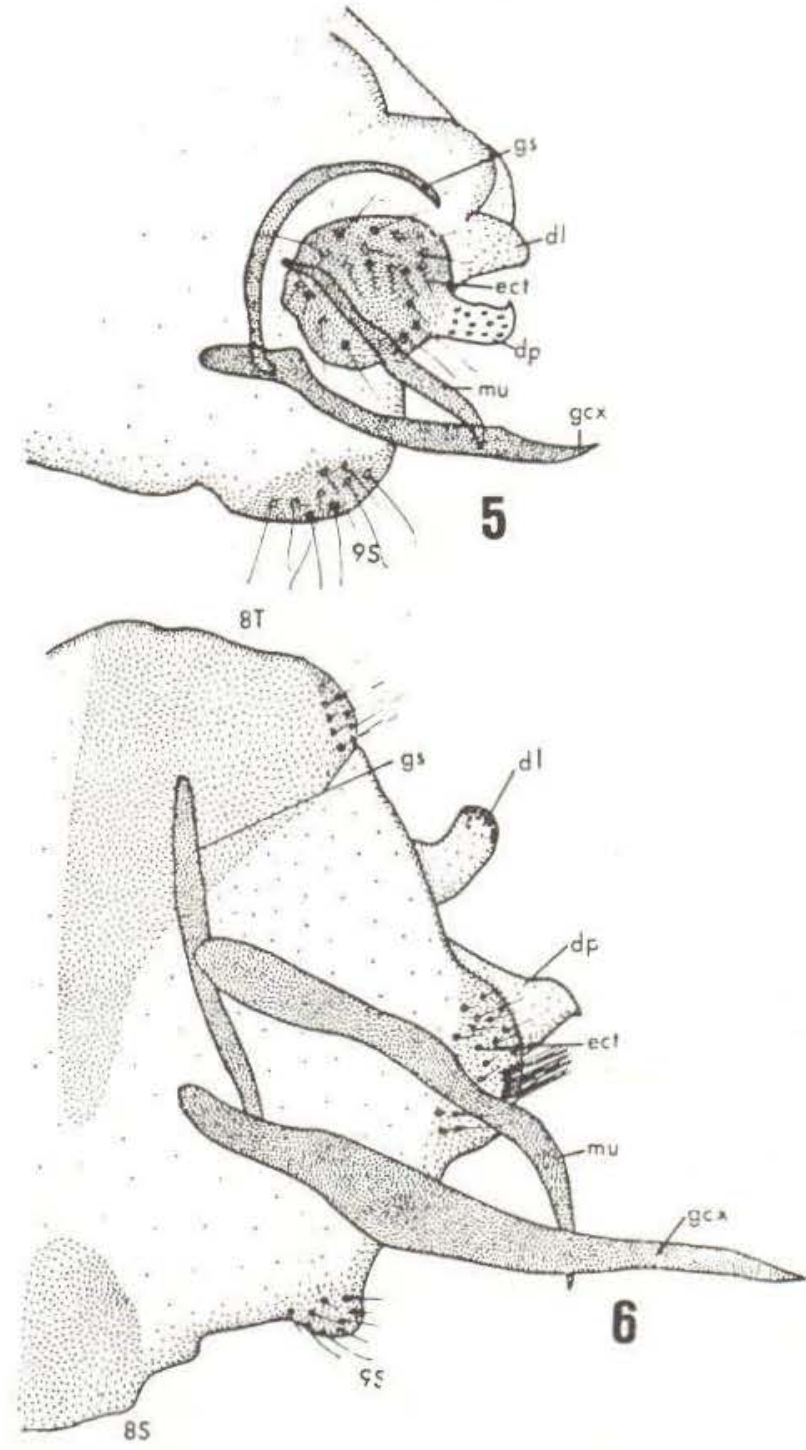

Figs. 5-6 - Lateral view of male gnitaeli of 5) Nallachius infuscatus, n. sp., 6) Nallachius adamsi, n. sp., $d l=$ dorsal lobe, $\mathrm{dp}=$ digitiform process, ect $=$ ectoproct, $\mathrm{gcx}$ $=$ gonocoxite, $\mathrm{gs}=$ gonarcus, $\mathrm{mu}=$ mediuncus

Forewing: Pale with numerous diffuse, coalescing pale fuscous spots. Costal crossveins numerous with short intercalary veins between. Subcosta vein curved caudally at apex. Radial sector three-branched with terminal twiggings. MA appearing as lower branch of Rs. MP branched basad of Rs-MA fork. CuA apically forked. MP2 not coalesced with CuA (Fig. 2). Abdomen of Male: Abdominal segments 2-8 with dorsal, setiferous tubercles. Gonocoxites long, blade-shaped, acutely pointed; connected basally by arched gonarcus; Iongitudinally grooved. Beween gonocoxites two shorter, sigmoidally sinuous, acutely pointed mediuncus lobes (Figs. 5,8). Dorsal lobes of ectoproct 


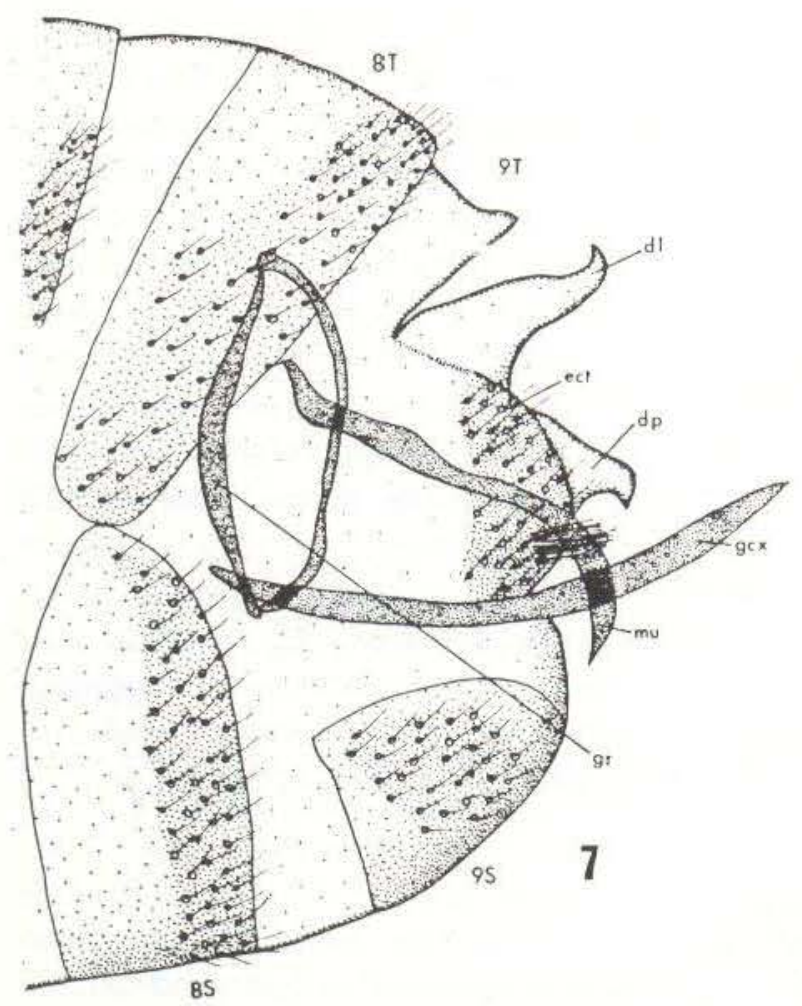

Fig. 7 - Lateral view of male genitalia of Nallachius maculatus, $\mathrm{n} . \mathrm{sp} ., \mathrm{dl}=$ dorsal lobe, $\mathrm{dp}=$ digitiform process, ect $=$ ectoproct, gcx $=$ gonocoxite, gs $=$ gonarcus, $\mathrm{mu}=$ mediuncus .

small, tubular, not approximated along midline. Digitiform process of ectoproct bulbous, with numerous pore openings, and apical hook.

Body Length: male, $2.0-3.3 \mathrm{~mm}$; female, $2.0-2.1 \mathrm{~mm}$.

Forewing Length: male, $2.9-5.3 \mathrm{~mm}$; female. $4.0-4.3 \mathrm{~mm}$.

Variation: There is a general variation in shade of forewing pigmentation and a large size difference, with some specimens being almost twice the size of others.

Geographical Distribution: Material in the Systematic Entomology Collection of INPA, Manaus include: BRAZIL: Amazonas, Reserva, Ducke, km 26 - AM 010, J. R. Arias, 2-V!II-1977, 1 male; 9-VIII-1977, 2 males; 6-IX-1977, 1 male; 6-XII-1977, 2 males; 27-XII1977, 1 male; 31-I-1978, 1 male; 14-II-1978, 1 male; 9-V-1978, 1 male; $16-\mathrm{V}-1978,1$ male; 6-VI-1978, 1 male; 27-VI-1978, 1 male; 13-IX1978, 1 male; Amazonas, $\mathrm{km}$ 52-BR 319, 26-1-1979, Eloy Castellon, 1 male; Amazonas. Manaus, Parque das Laranjeiras, 28-1-1981,
J.R. Arias 1 female; II-1981, 2 males; Amazonas, km 246- AM 010, 14-15-VII-1979, J.R. Arias, 2 males; Rondonia, km 48- BR 364, 27-IX-1979, J. R. Arias, 2 males; Rondonia Vilhena, 6-8-XI-1979, J. R. Arias, 9 males, 1 female: Rondonia, km 48- BR 364, 8-9-X-1979, S.U.C.A.M, 1 male, 2 females; Rondonia, km 50- BR 364. 17-X-1979, S.U.C.A.M., 1 male (Map 1).

Temporal Distribution: It appears that this species has a bimodal emergence from May to September and December to mid-February in the central Amazonian region, although it can be collected in October and November in Rondonia.

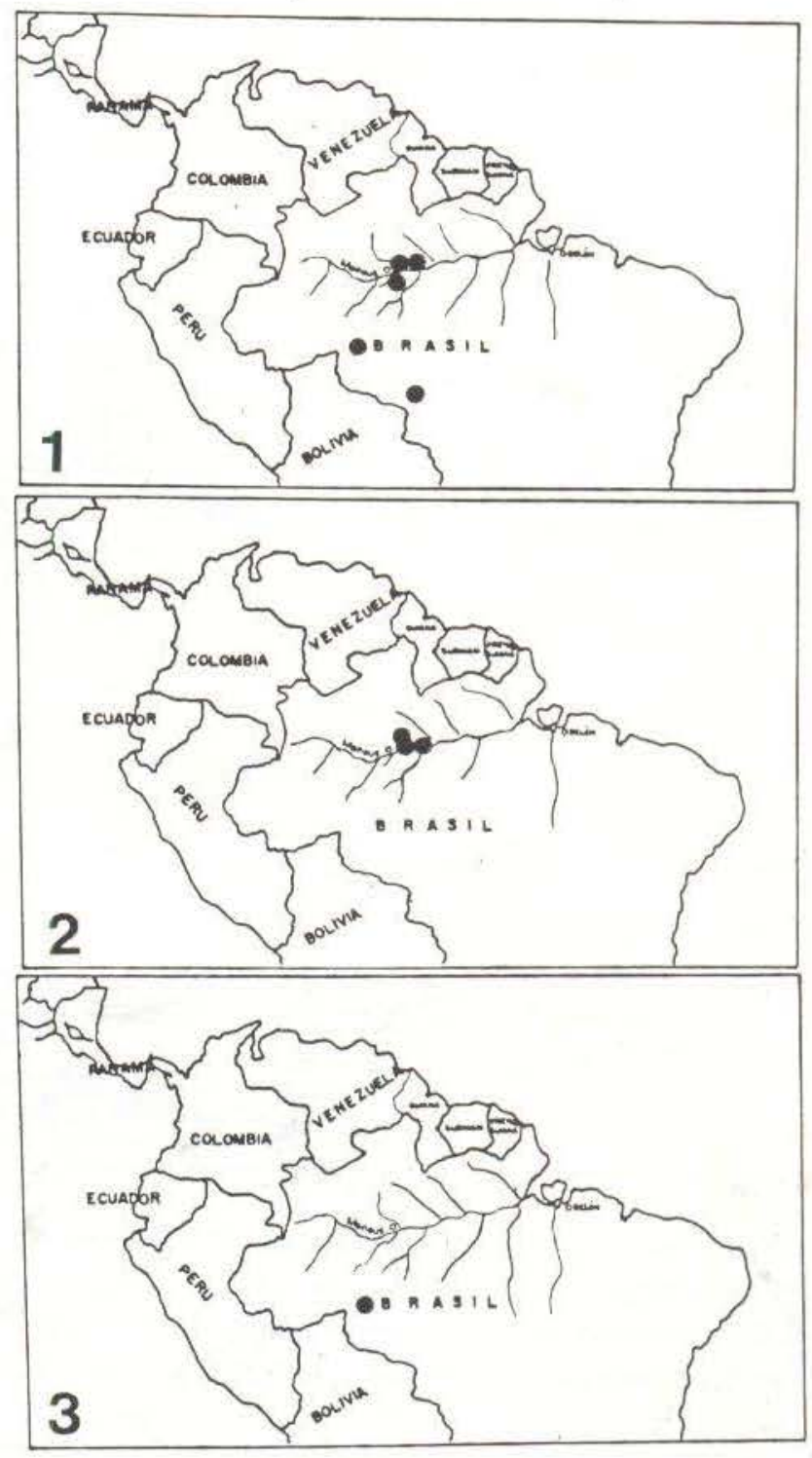

Maps 1-3 - Geographical distribution of 1) Nallachius infuscatus, n. sp., 2) Nallachius adamsi, n. sp., and 3) Nallachius maculatus, $\mathrm{n} . \mathrm{sp}$. 
Habitat: This species has only been collected from light traps set in the tops of trees in primary forest.

Holotype male (collected 6-IX-1977), allotype female (collected 6-XI-1979) and some paratypes in the Systematic Entomology Collection, INPA, Manaus. Further male paratypes (two each) in U.S. National Museum, Washington, D.C., U.S.A.; British Museum (Natural History), London, England; Museu Paraense Emilio Goeldi, Belém, Pará, Brazil; Museu de Zoologia, Universidade de São Paulo, São Paulo, Brazil; Museu Nacional, Rio de Janeiro, Brazil, and the Phillip A. Adams collection.

This species is a member of the pulchellus group having MP2 not coalesced with CuA.
$N$. infuscatus appears to be the smallest species of this group, and indeed of the whole genus, although $N$. prestoni is quite small and I have seen a specimen of $N$. dicolor which is much smaller than average for the species. The male genitalia for this group are very similar and differences hard to discern. However some differences do exist, and can be used. The dorsal lobes of the ectoprocts are developed and appear very similar to $N$. pres toni and $N$. reductus. The form of the costal region of the forewing, with no forked crossveins and apical curvature, separates $N$. infuscatus from $N$. prestoni. $N$. reductus ap. parently has narrow gonocoxites without apical, blade-like expansions, and no apical hook on the digitiform process of the ectoproct.

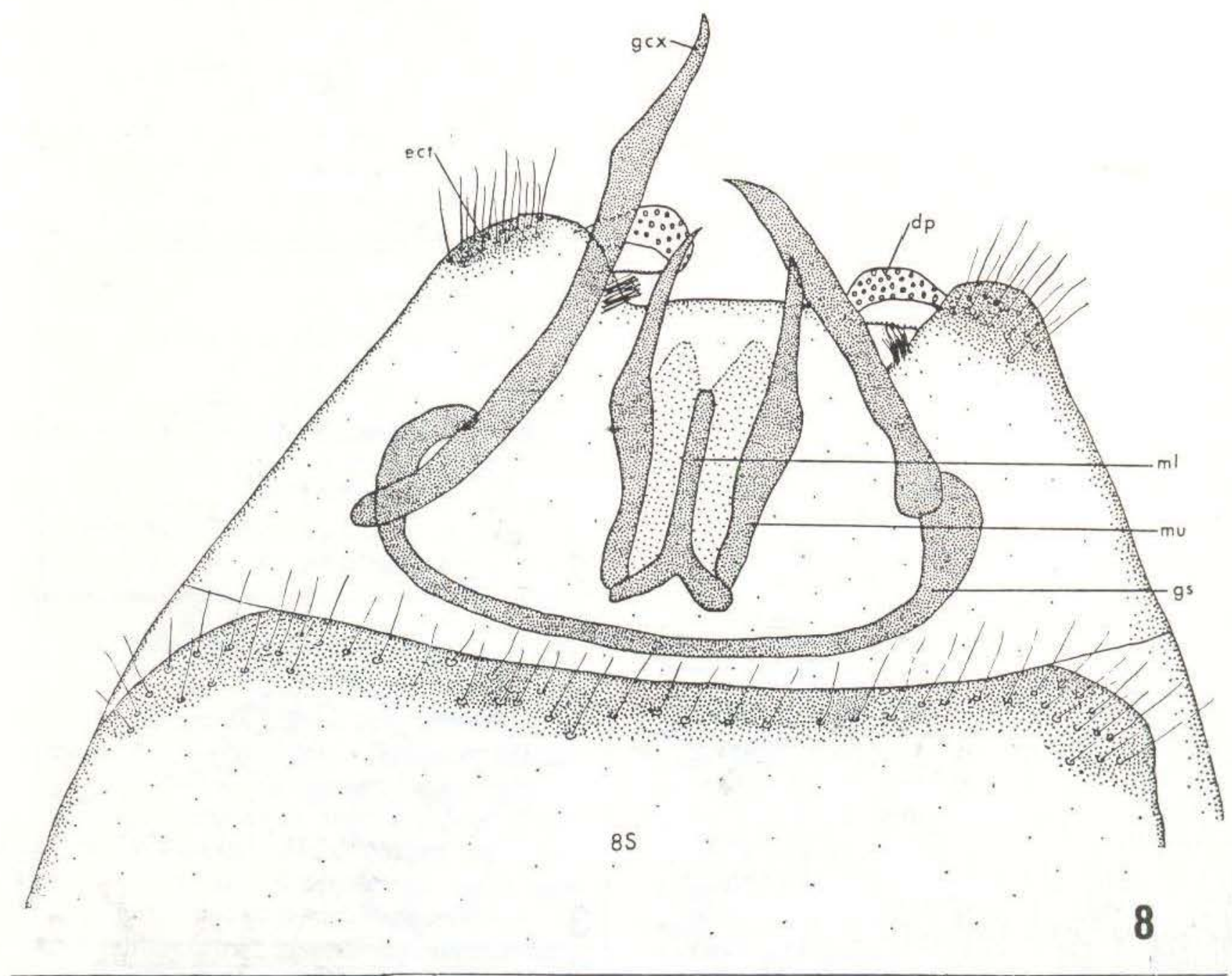

Fig. 8 - Ventral view of male genitalia of Nallachius infuscatus, n. sp. $d p=$ digitiform process, ect $=$ ectoproct, $\mathrm{gcx}=$ gonocoxite, $\mathrm{gs}=$ gonarcus, $\mathrm{ml}=$ median lobe, $\mathrm{mu}=$ mediuncus . 
Nallachius maculatus, n.sp.

(Figs. 4, 7, 10)

Holotype male in the Systematic Entomology Collection of INPA, Manaus. Original description based on 1 male, on slide, cleared in $10 \% \mathrm{KOH}$.

Head: Pink. Mouthparts tiny: labrum pale. Maxillary palpi three-segmented. Labial palpi reduced to small papillae. Antennae with only five segments remaining, with segments 2-5 bearing long, apical appendages in male.

Thorax: Clear, with dark pigment spot at base of each wing. Pleural region clear. What remains of legs clear, except tip of tibiae fuscous.

Forewing: Pale with numerous, small, dark fuscous spots. Eight spots along costal margin, the largest about halfway to wing apex. Three spots along anal margin. Costal crossveins numerous with short intercalary veins between. Rs four-branched with terminal twiggings. MA appearing as lower branch of Rs. MP unbranched, except for marginal fork. MP2 fused with CuA (Fig. 4).

Abdomen of Male: Abdominal segments 2-8 with dorsal, setiferous tubercles. Posterior margin of ninth tergite forming a medial point: dorsal lobes of ectoprocts large, terminally approximated, apically pointed; digitiform process with stout hook protruding near apex. Gonocoxites long, acutely pointed, without longitudinal groove; connected basally by circular gonarcus. Gonarcus with dorso-lateral. weakly sclerotized connective, which when viewed dorsally gives the gonarcus a double oval configuration (Fig. 10).

Between gonocoxites two shorter, ventrally curved, acutely pointed mediuncus lobes Fig. 7) .

Body Length: male, $3.8 \mathrm{~mm}$.

Forewing Length: male, $4.6 \mathrm{~mm}$.

Damage: The apical part of both antennae are broken off, leaving only five basal segments. Only parts of two legs remain, and wings are torn.

Geographical Distribution: The only known specimen of this species was collected at BRAZIL: Rondonia, $48 \mathrm{~km}$ east of Porto Velho, 1-XI-1979, J.R. Arias (Map 3).
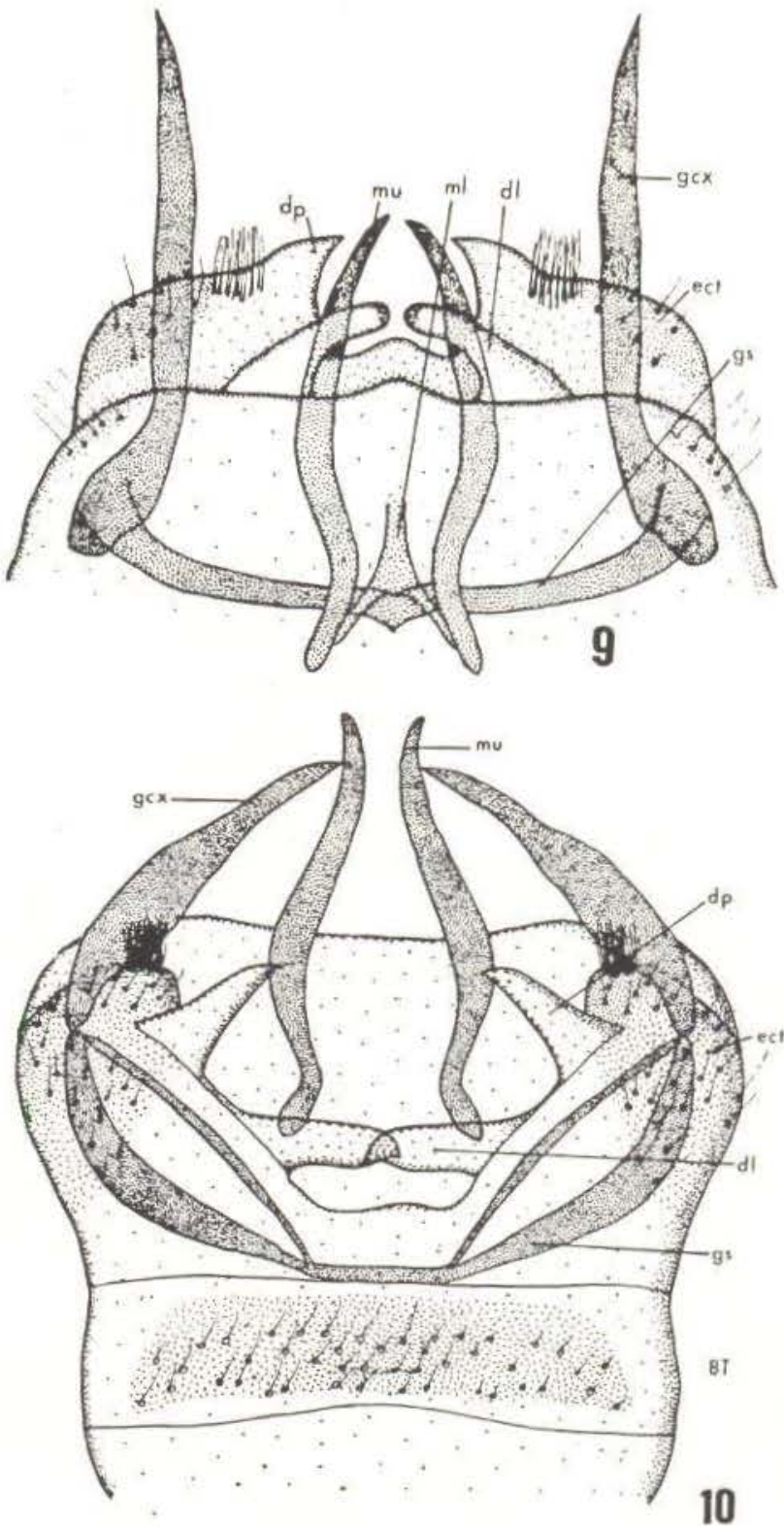

Figs. 9-10 - Dorsal view of male genitalia of 9) Nallachius adamsi, n. sp., and 10) Nallachius maculatus, n. sp., $\mathrm{dl}=$ dorsal lobe, $\mathrm{dp}=$ digitiform process, ect $=$ ectoproct, gcx $=$ gonocoxite, $\mathrm{gs}=$ gonarcus, $\mathrm{ml}=$ median lobe, $\mathrm{mu}=$ mediuncus.

Temporal Distribution: The only known specimen was collected on the first of November. Habitat: The holotype was collected in a C.D.C. miniature light trap, 10 meters high in the forest canopy.

This species is part of the americanus group, having MP2 of the forewing fused with CuA. The rounded wing and extensive "twig. 
ging" at the end of the longitudinal veins allies it most closely with $N$. pupillus Navás. The extra branch of the Rs separates $N$. maculatus from N. pupillus.

This species is named for the numerous spots on the wings, from the Latin word maculatus.

\section{ACKNOWLEDGMENTS}

Dr. Jorge R. Arias has collected almost all the material used in this study while doing field research on vectors of cutaneous leishmaniasis. Very small light traps were utilized in the forest canopy, and the resulting abundant material is gratefully acknowledged. Dr. Phillip A. Adams has looked over, and corrected, two early drafts of this manuscript, as well as comparing specimens of $N$. adamsi with $N$. americanus, and giving this author many valuable notes. His help has been tremendous, and he is to be greatiy thanked for this effort, although all errors of content remain those of the author.

\section{Resumo}

Três novas espécies de Nallachius (Neuroptera: Dilaridae) são descritos da Bacia Amazônica.

\section{LITERATURE}

ADAMS, P.A.

1970 - A review of the New World Dilaridae. Postilla, 148: $1-30$.

CARPENTER, F.M.

1947 - Taxonomic notes on the Dilaridae (Neuroptera). Psyche, Camb., 54: 100-109.

MacLACHLAN, $R$.

1880 - Occurrence of the neuropterous genus Dilar in South America. Entomol. Monthly Mag., 17: 39 .

MacLEOD, E.G. \& SPIEGLER, P.E.

1961 - Notes on the larval habitat and developmental pecularities of Nallachius americanus (MacLachlan) (Neuroptera: Dilaridae), Proc. Ent. Soc. Wash., 63: 281-286.

NAVAS, L.

1909 - Monografía de la familia de los Dilaridos (Ins. Neur.). Mems. R. Acad. Cienc. Artes Barcelona, 7: 619-671, 2 pls.

1914 - Neuroptera. Fam. Dilaridae. Genera Insect., 156: $1-133$

(Aceito para publicaçäo em $11 / 01 / 80$ ) 